\title{
Investigation of Different Cutting Technologies in a Ship Recycling Yard with Simulation Approach
}

\author{
Sefer Anil Gunbeyaz ${ }^{1}$, Rafet Emek Kurt, Osman Turan \\ The University of Strathclyde, Department of Naval Architecture, Ocean and Marine \\ Engineering, 100 Montrose Street, G40LZ, Glasgow, U.K.
}

\begin{abstract}
Ship recycling has drawn significant attention in the last decade due to the poor work practices in the industry, which led to the development of new international regulations. As a result, the operational costs of a ship recycling yard will increase since the new regulations are require more stringent standards for preserving the occupational and environmental health and safety of the people involved in ship recycling activities. The challenge for the ship recycling industry is to comply with the new regulations while staying profitable. Therefore, improvement of the current operational procedures and current levels of productivity will be critical to survive in a competitive industry dominated by low-cost substandard yards. Therefore, the main aim of this study is to increase the productivity of the ship recycling yard through the improvement of recycling processes. In this study, cutting operation in the secondary zone of a yard is investigated using discrete event simulation approach. Alternative cutting technologies have been tested in a simulation environment in order to assess their impact on production performance and operating costs. This study shows that plasma cutting is a good alternative to oxyfuel cutting in ship recycling and demonstrates that $60 \%$ improvement in the throughput can be achieved through the implementation of the tool. Overall research conducted in this study will be significant contribution to the maritime literature as a novel approach for modelling ship recycling processes and for the implementation of cutting technologies to operations.
\end{abstract}

\section{Introduction and background information}

Ship recycling is the last step of the ship's life cycle (Kurt et al., 2017) and the most environmentally friendly option where $95-98 \%$ (as weight) of the ship's materials and equipment are recycled (McKenna et al., 2012, Jain and Pruyn, 2017). Every year, around 1000 ships are recycled around the world (NGO Ship Breaking Platform, 2017), recycling the raw materials, creating revenue, employment and supporting development (Yanmaz, 2005). When hazardous materials are properly handled, and raw materials are effectively recycled ship recycling industry may significantly contribute to developing countries economy by providing the raw materials for many industries (Gunbeyaz et al., 2019).

Today, ship recycling is mainly carried out by five major countries, Bangladesh, India, China, Pakistan and Turkey. These five countries are leading the industry by the volume as $98 \%$ of ships are recycled in those countries listed above (Mikelis, 2013). However, ship recycling practices in these countries are heavily criticised due to the damage it causes to the health of the workers, the environment and the local community (Kurt et al., 2017, Rabbi and Rahman, 2017, Singh et al., 2020). According to the NGO-Shipbreaking Platform (NGO, 2015) thousands of workers lost their lives (NGO Ship Breaking Platform, 2017) in ship-recycling facilities in South Asia. Toxic waste from ships not only exposes the workers to hazardous materials but also contaminates the coastal environment (Reddy et al., 2004, Asolekar, 2006,

*Corresponding author: Tel: +44 (0)141548 4116 | Email: sefer.gunbeyaz@strath.ac.uk 
Neşer et al., 2008, Mahindrakar et al., 2008, Demaria, 2010, Chang et al., 2010, Garmer et al., 2015, Hiremath et al., 2015, Hiremath et al., 2016, Eronat et al., 2019). Due to the poor working practices in yards, and unregulated waste management practices, workers and communities have been harmed directly and indirectly (Hossain et al., 2008, Salim, 2009, Hossain et al., 2016, Ozturkoglu et al., 2019). Many sources indicate that, biodiversity of the coastal waters is degraded, numerous species were lost and fishing activities were reduced which directly impacted on the local community who belong to the most disadvantaged parts of society (Sinha, 1998, Hossain and Islam, 2006, NGO Ship Breaking Platform, 2017). Furthermore, research shows that environmental impacts caused by ship recycling activities cannot be reversed even after 10 years and toxic substances contaminated the food chain and transferred into wildlife feeding from sea (DIVEST, 2012).

These concerns forced policymakers to take action and currently ship recycling industry is going through a transitionary period due to the regulatory changes (Hong-Kong Convention (IMO, 2009) and EU Ship Recycling Regulation (EC, 2016)). As a result of these upcoming regulatory changes, the cost of current ship recycling yards is expected to increase as part of the investments required to comply with regulations including HSE measures (Gunbeyaz et al., 2018). Therefore, in order to assist ship recycling yards with their investment decision, there is a need for demonstrating that the revenue of the recycling yards can be increased through more effective recycling procedures and technology. Moreover, In China, recycling is limited to domestic tonnage as of $1^{\text {st }}$ January 2019 and this loss in global recycling capacity can be compensated through these effective recycling procedures and technology.

In order to understand the problems and to support the yards, a typical ship recycling operation should be investigated initially. The first step in the recycling of a vessel in a yard is to secure the ship in the primary zone of the yard which is generally located in the sea-shore interface zone (after the appropriate checks have been carried out by the authorities). After securing the ship to be recycled, an initial investigation into the hazardous materials on board are conducted (TSRA, 2009). The identified hazardous waste is removed from the ship before starting to dismantle the equipment and machinery. Once the hazardous waste is removed, the ship is cut into sections and transferred to the secondary cutting zone where these sections are further cut into smaller pieces, which is a technical requirement by the smelter as it makes transportation easier. For example, in the ship recycling zone in Aliaga/Turkey, some yards prepare the plates with maximum dimensions of 1 meter in length and 1 meter in width while others prepare in smaller sizes (IDC, 2017).

Majority of the field studies conducted showed that secondary cutting zone sets the limitation on the production capacity of the yard and forms a bottleneck in the reverse production line. When the blocks in the secondary cutting cannot be handled fast enough, the block storage area becomes insufficient, and new blocks cannot be transferred in. When the secondary area is full, the production in the primary cutting zone needs to be stopped which delays the clearance of the primary zone for the new ships which, in long-term, decreases the dismantling capacity of the ship recycling yard. One of the reasons that may lead to this problem is the low production rate of the oxy-fuel torch cutting. Furthermore, there is always a risk of fire especially when the bottom block, which is covered with paint and oil residues, are being processed. During yard visits, it was observed that the cutting process is repeatedly interrupted due to ongoing small fires until the fire is put out. If a faster and safer method for secondary zone cutting can be identified the bottleneck in the secondary zone can be 
resolved. Changes in cutting methods during cutting would also reduce the environmental and health impacts (Rahman et al., 2016).

Ship recycling can be approached as reverse shipbuilding (Alkaner et al., 2006b, Gunbeyaz, 2019), therefore, the productivity issues can be solved imitating the approach of ship building and repair yards. Researchers and industry professionals approached the similar problems for shipbuilding and repair yards through different methodologies and approaches including simulation (Ju et al., 2020, Goo et al., 2019, Woo and Oh, 2018, Basán et al., 2017, CebralFernández et al., 2017, Velumani and Tang, 2017, Prajapat et al., 2016, Shin et al., 2009, Song et al., 2009), lean manufacturing (Sharma and Gandhi, 2017, Phogat, 2013, Kristoffersen, 2012, Koenig et al., 2002), or utilisation of technology for digital yards, production network and accurate manufacturing (Sender et al., 2019, Jagusch et al., 2019, Wei et al., 2019, Zhang et al., 2012). However, considering the nature of ship recycling yards, lack of data, and lack of industry-research collaboration, some of these approaches are too advanced for ship recycling industry. Therefore, simulation approach is more suitable approach for implementation to ship recycling industry. At this point, discrete event simulation provides us with a promising technique to model, simulate and optimise yard procedures in a framework which is widely used and proven in other sectors. Therefore, this study will apply discrete event simulation as a tool for optimising ship recycling yard procedures. Therefore, the main aim of this study is to increase the productivity of the secondary dismantling zone of a ship recycling yard by identifying and testing different cutting technologies for ship recycling operations. By using discrete-event simulation methods and Arena ${ }^{\circledR}$ Discrete Event Simulation software, the secondary cutting zone of a ship recycling yard was modelled and cutting operation was simulated for identified cutting technologies.

This study will be the first study in the literature addressing the important gap of improving productivity in ship recycling and implementing the simulation at this scale. The literature focusing on the productivity (and utilising simulation) area is extremely limited due to lack of data, access to yards and lack of understanding of ship recycling procedures. This study also addresses this important gap through mapping the procedures, collecting operational data. Through the utilisation of the simulation, this study proves that alternative production options are possible for ship recycling and the increased revenue stream can be utilised. Moreover, the implementation of a cutting technology to substitute the current low-cost oxyfuel cutting technology has not been conducted for ship recycling area. This study reviewed the possible technologies, collected data and run simulations in a real case study to investigate the implementation possibility of these technologies. This is also a unique contribution to the literature in ship recycling as well as the simulation literature. 


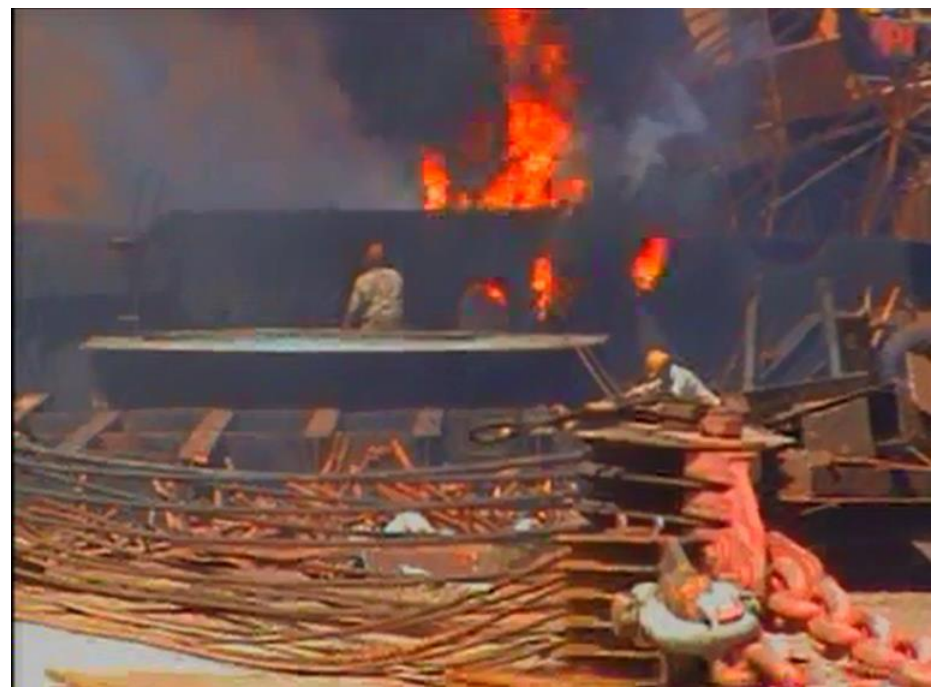

Figure 1: Fire caused by burning the residues on blocks

This study first reviews the literature to understand the studies and gaps in the literature in section two. Then Section 3 explains the approach of the research, while section 4 demonstrates the implementation of the simulation within the secondary cutting zone. Section 5 demonstrates the results of the simulation, and sections six and seven discusses the findings and conclusions.

\section{Literature Review}

Today, the ship recycling industry is going through a transitional phase where scientific support and technical approaches are needed more than ever before. One of the solutions for the capacity problem mentioned above is to increase the efficiency and productivity of the ship recycling facilities through optimisation of the ship recycling processes. Optimising the ship recycling processes will not only decrease the costs, but it will also increase the output of the yards, increase the earnings and in the long term it will increase the capacity of the yards. No study within the current body of literature focuses on increasing the productivity of the ship recycling facilities. Manufacturing, production, service and similar industries address their productivity problems through detailed simulation approach and to optimise the way they work. Therefore, a similar approach is needed for the ship recycling industry. Modelling and simulation studies in the literature (Creese et al., 2002, Ahluwalia and Govindarajulu, 2005, Adamides et al., 2006, Alkaner et al., 2006a, Pylarinou et al., 2008, Koumanakos et al., 2006, Pylarinou et al., 2006) for ship recycling focus on the simple calculation of costs and revenue but do not go into the detail of improving the situation or addressing any productivity problems. Similar studies exist in the literature for shipbuilding yards, port operations and maritime operations and are being utilised to improve the ship design and maritime operations. However, this approach has not been applied to the ship recycling industry as it requires extensive data and investigation of different recycling processes.

Simulation is the representation of operation, process or system in real world over time which allows predicting the steps and the problems at any stage (Banks, 2005, Ljubenkov et al., 2008). It is widely used in the manufacturing industries to reduce production time and cost of the process and products. Problems encountered in the systems can be modelled, and different options can be tested with simulation methods. Simulation approach has been widely used to optimise the process in manufacturing industries, to increase the service quality in the 
hospital, to optimise the service and schedules of different transport methods (e.g. airport, train, metro), to increase the performance of call centres, and to design facilities in manufacturing and de-manufacture industries.

The simulation approach also used by some researchers in the ship recycling area. A simulation-based Decision Support System for collaborative modelling and management of ship recycling processes was developed by Pylarinou et al. (2009). Even though the tool developed is a good starting point, the tool and the method have some deficiencies. First, ship recycling process of the tool is not transparent, does not cover all the activities in the ship recycling yard, and does not provide the user with the flexibility to change the order of the process or add new processes. Ahluwalia and Govindarajulu (2005) developed a web-based tool which can be used to estimate ship recycling costs, to view the inventory of ships, to view construction details of a ship and to determine the number of petroleum products on board. However, the tool can only make simple calculations based on the parameters defined, and it lacks the detailed analysis for the productivity. Therefore, it does not address the need of the industry on detailed optimisation of the procedures.

Specifically, in the ship recycling industry, there are not many studies that investigate the performance of different technologies for cutting steel. The most comprehensive study, DIVEST (2008-2011), developed a value model as part of the EU funded FP6 project. One of the aims of the developed value model was to compare different ship recycling options. In the report, one of the case studies was to compare oxy-acetylene cutting to the oxy-propane torch (DIVEST, 2011). However, this study only approaches the problem on the economic perspective, and there is no in-depth productivity analysis as part of this study. DIVEST also assessed the feasibility of different cutting and surface cleaning technologies (DIVEST, 2009b). In this study, key performance indicators (such as technology readiness level, Investment, installation cost, and so forth) were defined and assessed for each technology with these key performance indicators whether these methods were usable in ship recycling or not. Moreover, authors of the report have collected information about cutting rates, costs, technology readiness levels, benefits and disadvantages (DIVEST, 2009a). However, this study was only at a theoretical level and only used for estimations of the performance and operation costs. Even though this study provides a good starting point, it does not include indepth information on the practical implementation of these cutting rates.

McKenna and Das (2008) proposed different cutting and removal methods such as caustic stripping, ice jetting, water jet blasting and cutting, sponge jet blasting and mobile shears to improve the ship recycling with regards to safety, economy and environment. However, the study was limited to health and safety improvement suggesting alternative methods only without any in-depth investigation.

Deshpande et al. (2010) conducted a time-motion study to estimate the inputs (labour, oxygen and fuel) and outputs (emissions to air as well as deposition of paint and steel on intertidal sediment) during the cutting operation using oxy-fuel torches. The analysis of inputs showed that $6.2 \mathrm{~kg}$ of fuel is consumed per $\mathrm{km}$ of plate cut per mm plate thickness. On the output side, $\mathrm{CO} 2$ emissions were estimated as $21.77 \mathrm{~kg}$ per $\mathrm{km}$ of plate cut length per $\mathrm{mm}$ of plate thickness (Deshpande et al., 2010). Findings of this study can be utilised to estimate the $\mathrm{CO}_{2}$ emissions and to find the $\mathrm{CO}_{2}$ reductions after the optimisation process. 
In 2010, a pilot project was conducted in a ship recycling yard to test different ship recycling techniques including waterjet cutting (Urano, 2012, Shimizu et al., 2012). In this study, 45,706 GT Pure Car Carrier was selected as a case study and all the steps of the recycling operations were reported (Urano, 2012). As part of this pilot project, waterjet cutting was also considered for application on ship recycling. A special waterjet cutting machine was developed, which is lighter and stronger than usual waterjet cutting machines (Urano, 2012). This study demonstrated the possible use of waterjet cutters in ship recycling yards, especially in the areas where there is high explosion and fire risks. One study that compares the plasma cutting and oxyfuel cutting is conducted by Rzeźnikiewicz (2014), analyse the economic performance (direct costs without labour costs) of cutting process in low alloy steels with various thicknesses.

The review of the studies also shows that there is a need for a comprehensive study to compare the cutting methods for the ship recycling industry. The summary of these studies is shown in Table 1.

Table 1: Summary of the studies on technology comparison for ship recycling

\begin{tabular}{|c|c|c|c|}
\hline $\begin{array}{l}\text { Author/ } \\
\text { Project }\end{array}$ & Year & Pro's & Con's \\
\hline $\begin{array}{l}\text { McKenna, } \\
\text { and Das }\end{array}$ & 2008 & $\begin{array}{l}\text { Investigation of } \\
\text { different technologies } \\
\text { for ship recycling } \\
\text { Investigation of key }\end{array}$ & $\begin{array}{l}\text { Limited to HSE improvement and } \\
\text { limited as a suggestion }\end{array}$ \\
\hline DIVEST & 2009 & $\begin{array}{l}\text { performance indicators } \\
\text { (TRL, investment, } \\
\text { installation cost. etc.) }\end{array}$ & $\begin{array}{l}\text { Theoretical level, no in-depth } \\
\text { information on practical } \\
\text { implementation. }\end{array}$ \\
\hline $\begin{array}{l}\text { Urano et } \\
\text { al. }\end{array}$ & 2012 & $\begin{array}{l}\text { Investigation of } \\
\text { waterjet cutting } \\
\text { machine }\end{array}$ & $\begin{array}{l}\text { Good practical implementation in an } \\
\text { actual case but does not provide } \\
\text { quidance for future studies. }\end{array}$ \\
\hline
\end{tabular}

As a starting point, DIVEST project's technology list were utilised and following technologies were investigated; (1) Oxy acetylene, (2) Abrasive Waterjet, (3) Plasma, and (4) Laser. However, considering that the laser cutting is relatively a new technology, and the initial cost of laser cutting equipment is exceptionally high (£50,000+). Also, the operation of the laser cutting equipment requires specific measures for health and safety, while the mobility of the laser cutting system is very limited. Considering the nature of the ship recycling, laser cutting system will not be assessed as part of this study. To sum up, three technologies are decided to be analysed further in this part of this study. As the current technology, oxy-fuel cutting will be included in this study. In order to establish a baseline and compare it to other methods, oxyfuel cutting approach will be investigated. Secondly, plasma cutting technology will be investigated as it is a modern and strong alternative to oxyfuel cutting. Lastly, abrasive waterjet cutting will be investigated to demonstrate the different cutting approaches and their feasibility in the ship recycling industry.

\section{Approach}

This study investigates the feasibility of applying alternative cutting methods to oxyfuel cutting in the scope of ship recycling operations. The overall approach of this study is shown in Figure 2. 


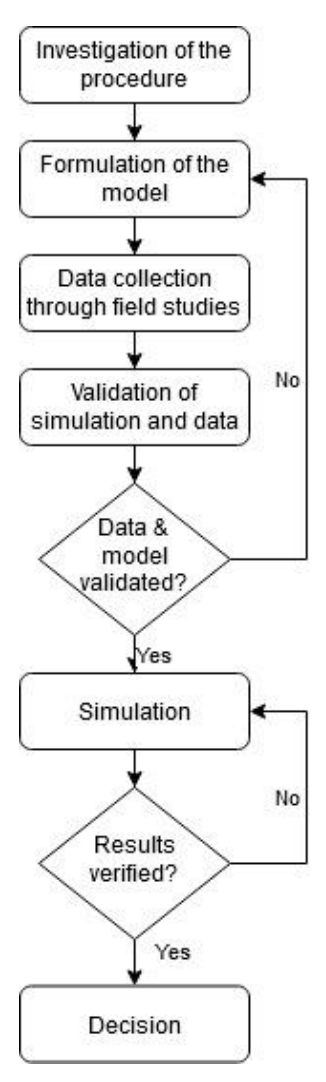

Figure 2: Approach of the study

First, the procedure in the ship recycling yard was investigated to develop the simulation model. Next, dismantling operation in the secondary dismantling zone was modelled in accordance with the existing procedure in a ship recycling yard. The required operational data for oxy-fuel cutting were collected and tested the theory "can we use the manufacturer's data for cutting performance instead of actual operation data?" through a simple case study of block dismantling. Simulation results comparing the field study and manufacturer data demonstrated that using the manufacturer data is valid, the study continued with data collection for plasma cutters and waterjet cutters. Possible dismantling options for the selected blocks were modelled using the discrete event simulation approach using the Arena simulation model. Finally, the identified options were compared in the simulation environment to find the best option regarding the productivity.

\section{Implementation}

In the DES, the term "system" is often used for describing the case which is under investigation. In this study, secondary zone process of a ship recycling yard was simulated. Therefore, "system", in the scope of the study, refers to the secondary zone cutting. A ship recycling yard (that cannot be named due to a confidentiality agreement) which is operating under EU norms was selected as a case study for this paper. The yard in this study has obtained the necessary certificates including but not limited to ISO 30000 , ISO 9001, and ISO 14001.

\subsection{Investigation of the procedure and formulation of the model}

This ship recycling yard was investigated to identify the procedures and to create the process flow. The procedure for dismantling a block in the yard has been observed, and the process 
flow shown in Figure 3 was developed to facilitate the modelling. Resources associated with each step is also shown in the figure below.

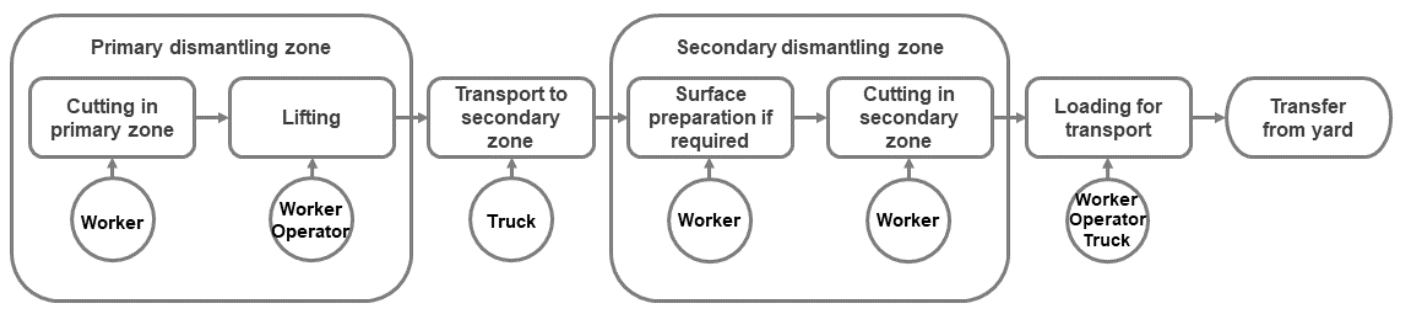

Figure 3: Simplified process flow of a block and associated resources in primary and secondary cutting zones

First, blocks are cut and removed from the ship, and they are transferred to the secondary cutting zone using a crane and trucks. In the secondary zone, these blocks are further cut into smaller pieces by the workers. Foreman only has a supervisory role in these areas. Therefore, foreman is excluded in the simulation. Considering that the hot cutting methods are prevalent method of cutting in ship recycling yards, surface preparation may be used to prevent the release of toxic gases and fumes in the air. Surface preparation includes removal of paints, coatings, even flammable (e.g. fuel and oil residues) substances, from the metallic surfaces before starting the cutting work. In the yards we observed, small fires on the cut blocks were a common hazard due to the contaminated surfaces. In addition, surface preparation is also important that the metallic surface is sometimes painted with toxic paints which include heavy metals (e.g. lead), PCBs etc. Therefore, for health safety and environmental protection, surface preparation is a procedure that needs to be considered for ship recycling operations.

\subsection{Data Collection}

As a next step in the study, a data collection study was conducted through field studies and desktop study. Operational and manufacturer's data (production rates on given thickness and costs) on the selected cutting technologies were collected. Details of the data collection step is summarised below.

\subsubsection{Observation study}

In order to collect the needed data on oxyfuel cutting, a field study was conducted in a ship recycling yard. Recycling of a block was observed and recorded during this field study which starts with cutting on board and ends with the transportation of the block out of the yard.

The selected block (Figure 4) is a common type of accommodation block on the ship with dimensions; width: $3.0 \mathrm{~m}$, Height: $2.0 \mathrm{~m}$, Length: $3.5 \mathrm{~m}$ and the thickness of the steel is 15 millimetre. Furthermore, the height of the stiffeners is 0.1 meters. 


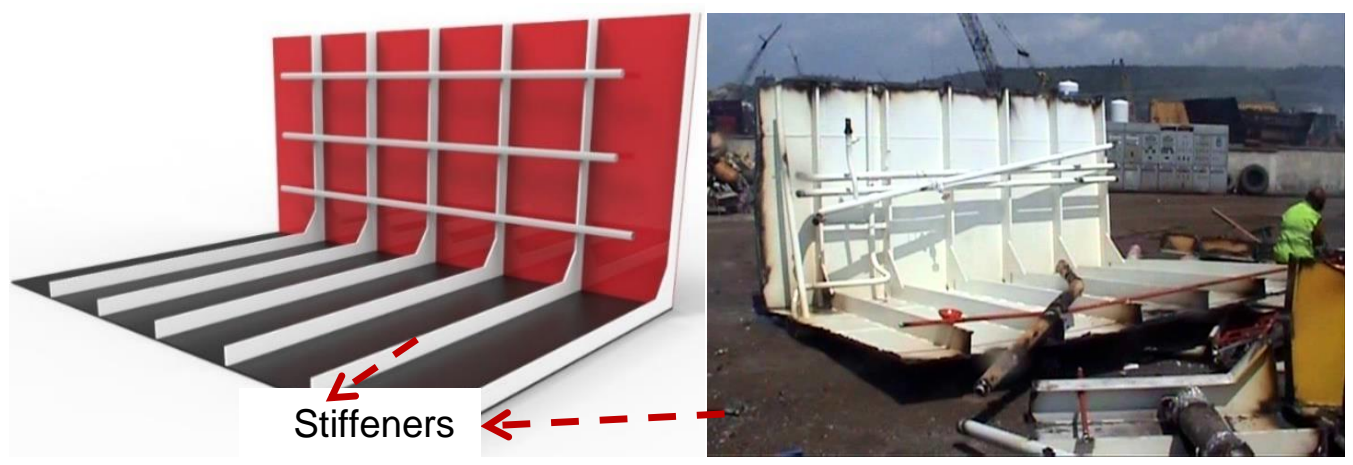

Figure 4: Selected block for data collection study.

During the field study, it was observed that the cutting operation consists of two steps; preheat and piercing the steel and cutting. Therefore, cutting performance of the worker has been investigated in two different steps as well. In order to do this analysis, preheat and piercing times were deducted from the total cutting time and actual cutting time was found. Then the cutting time divided by the cutting distance to find the average cutting speed per minute. The average cutting speed of the torch during horizontal cutting is calculated (approximately) 600 $\mathrm{mm}$ per minute. Moreover, during the vertical cutting, the average cutting speed of the worker is reduced to $300 \mathrm{~mm}$ per minute. The difference in the cutting speed is caused by the positioning of the torch and the worker. During the simulation, the effect of the worker's positioning is also considered by decreasing the production rate by $50 \%$, like the worker's performance in data collection study.

\subsubsection{Manufacturer data}

The manufacturer data of the equipment was also collected for comparison and validation. In order to compare the current oxy-LPG cutting method with the plasma cutting, portable plasma cutting systems were investigated in detail. Interviews with manufacturers and ship recyclers were conducted to find the most suitable plasma cutting kit, and as a result, two different plasma cutting kit with different cutting range were selected. One of the kits (Plasma B) is for general use to cover all the thickness range in the recycling yard, and another kit (Plasma A) specifically selected for the steel thickness of the block. The production data for a mobile waterjet cutter is taken from DIVEST project's state of the art report (DIVEST, 2009a). The overall cutting speed provided by the manufacturer's data sheet used for all the methods investigated.

\subsection{Simulation Model}

In order to simplify the modelling, a generic model was created, then, sub models were developed within the generic model. For this study, two blocks, which were removed from an end-of-life ship were selected; a block from the accommodation area and double bottom block (Figure 5). The thickness of the accommodation area block is uniform throughout and it is 15 millimetres. The dimensions of the bottom plate are 3500 to 2700 millimetres. The vertical plate is 2700 millimetres in height and 3500 millimetres in length. The weight of the block is approximately 2.8 tons. The overall dimensions of the double bottom block are 4150 millimetres in length, 3350 millimetres in width and 1250 millimetres in height. The steel thickness of the block is uniform through the block, and it is 15 millimetres. 

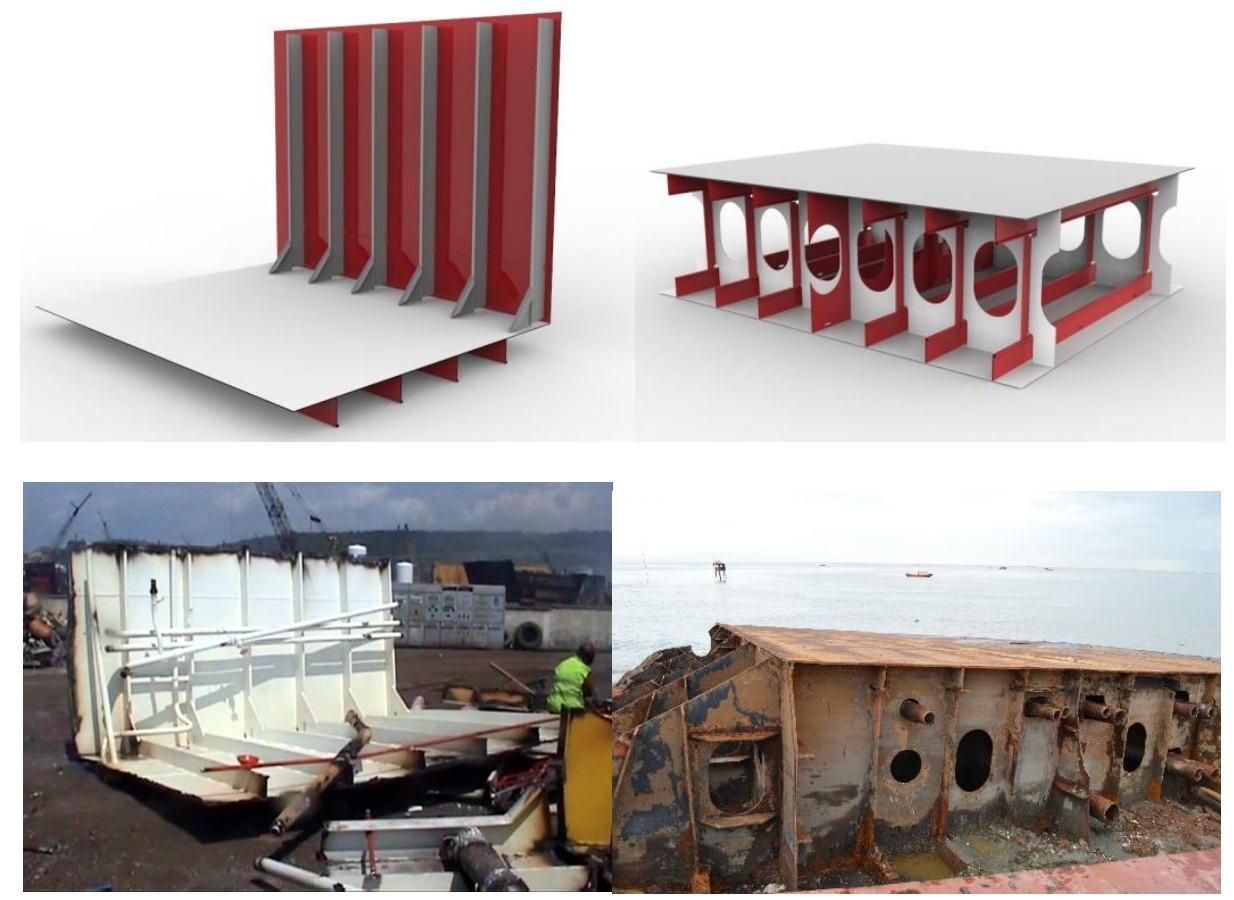

Figure 5: Accommodation area block (left), double bottom block (right)

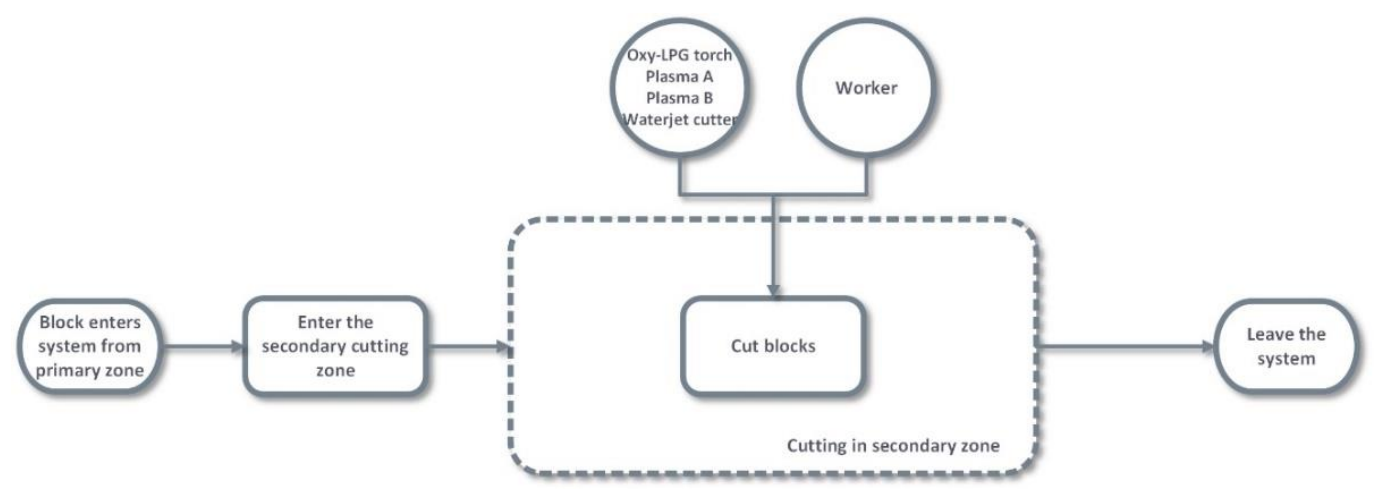

Figure 6: Simplified representation of the generic model for no surface treatment case

The simplified representation of the generic model is shown in Figure 6; a block enters the simulation system from the primary cutting zone and transferred to the secondary cutting zone. In the secondary zone, the block is cut into smaller pieces for transportation purposes and then leaves the system. This model applies to all the block cases that do not require surface treatment, as long as the module named "Cut Blocks" is designed as sub-model and altered for all blocks according to the cutting lines. In this model, resources allocated is the worker who will conduct the cutting and depending on the scenario, oxy-LPG torch, plasma or waterjet cutter. The models were then developed in the Arena simulation environment.

Similarly, the representation of the model for the cutting operation with surface cleaning is shown in Figure 7. This block also goes through surface cleaning before the cutting operation using waterjet blasting method. Like the no-surface cleaning case, this initial model is developed in the Arena simulation model. The main difference in this block is the Surface cleaning sub model which involves the surface preparation before the cutting operation. 


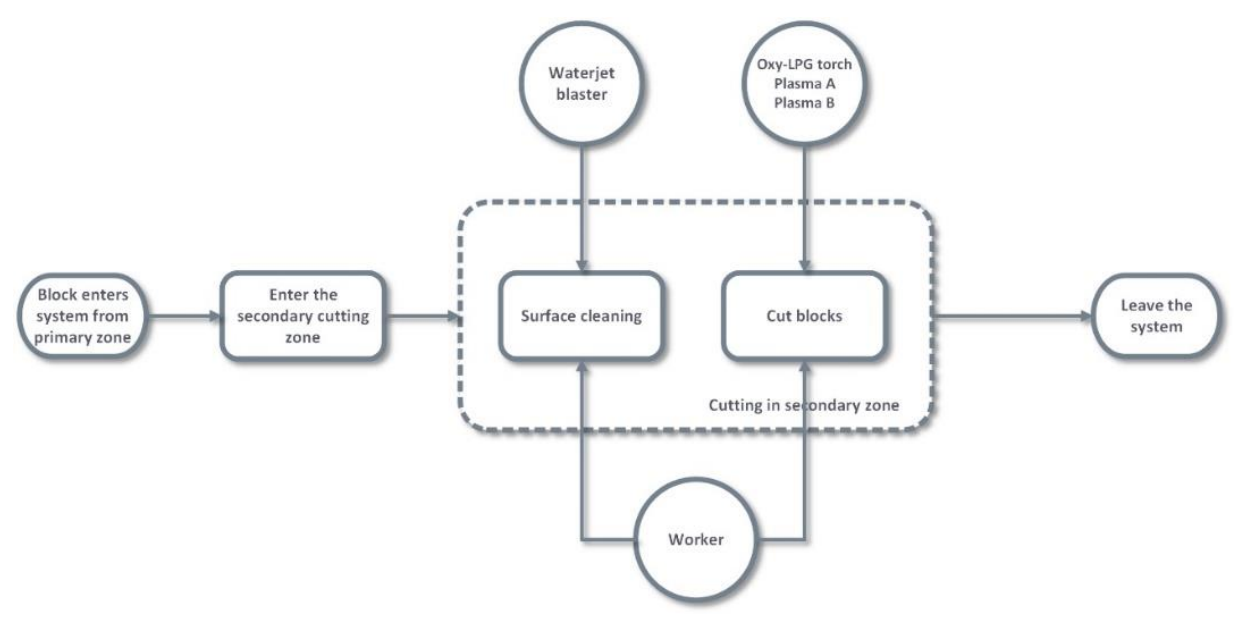

Figure 7: Simplified representation of the generic model for surface treatment case

\subsection{Validation of model}

It is important to validate the logic of the model before conducting a detailed analysis of different technologies. In order to validate the logic of the model, dismantling operation of the data collection block was simulated and the results of the simulation were compared with the observed data. The total dismantling time in the simulation and observed process were the same which demonstrated that the model works correctly. Moreover, the initial theory in this study was to use the manufacturer's data instead of operational data for the cutting operations. In order to test this theory, simulation is repeated using manufacturer's data which showed only less than $2 \%$ difference between the actual performance data and the manufacturer data (Table 2). Therefore, the manufacturer's data will be used instead of the observed data for the remaining analysis.

Table 2: Comparison between the manufacturer's data and Operational data

\begin{tabular}{lc}
\hline Source & Total Time (Min) \\
\hline Observed operation time & $61: 34$ \\
Model process time & $61: 34$ \\
Manufacturer data and distribution & $60: 12$ \\
\hline
\end{tabular}

\section{$5 \quad$ Results}

\subsection{Accommodation Area Block}

The simulation for the accommodation area block was run for ten repetitions. The average duration of each option for the dismantling operation is given in Table 3 and Figure 7.

Table 3: Duration of the operation for different process options

\begin{tabular}{ccccccc}
\hline $\begin{array}{c}\text { Oxy-LPG } \\
\text { manufactu } \\
\text { rer }\end{array}$ & Plasma A & Plasma B & $\begin{array}{c}\text { Waterjet } \\
\text { (min) }\end{array}$ & $\begin{array}{c}\text { Cleaning } \\
\text { \& Oxy- }\end{array}$ & $\begin{array}{c}\text { Surface } \\
\text { Cleaning }\end{array}$ & $\begin{array}{c}\text { Surface } \\
\text { Cleaning }\end{array}$ \\
data(min) & & & $\begin{array}{c}\text { Cutting Plasma } \\
\text { \& Plasma }\end{array}$ & $\begin{array}{c}\text { A (min) } \\
\text { B (min) }\end{array}$ & B (min) \\
\hline
\end{tabular}




\begin{tabular}{cccccccc}
\hline $\begin{array}{c}\text { Surface } \\
\text { cleaning } \\
\text { duration }\end{array}$ & - & - & - & - & $62: 55$ & $62: 45$ & $63: 07$ \\
$\begin{array}{c}\text { Total } \\
\text { duration }\end{array}$ & $107: 59$ & $63: 18$ & $43: 37$ & $251: 54$ & $167: 54$ & $126: 40$ & $106: 59$ \\
\hline Cost & $€ 33.07$ & $€ 26.09$ & $€ 20.17$ & $€ 96.13$ & $€ 55.52$ & $€ 46.89$ & $€ 43.72$ \\
\hline
\end{tabular}

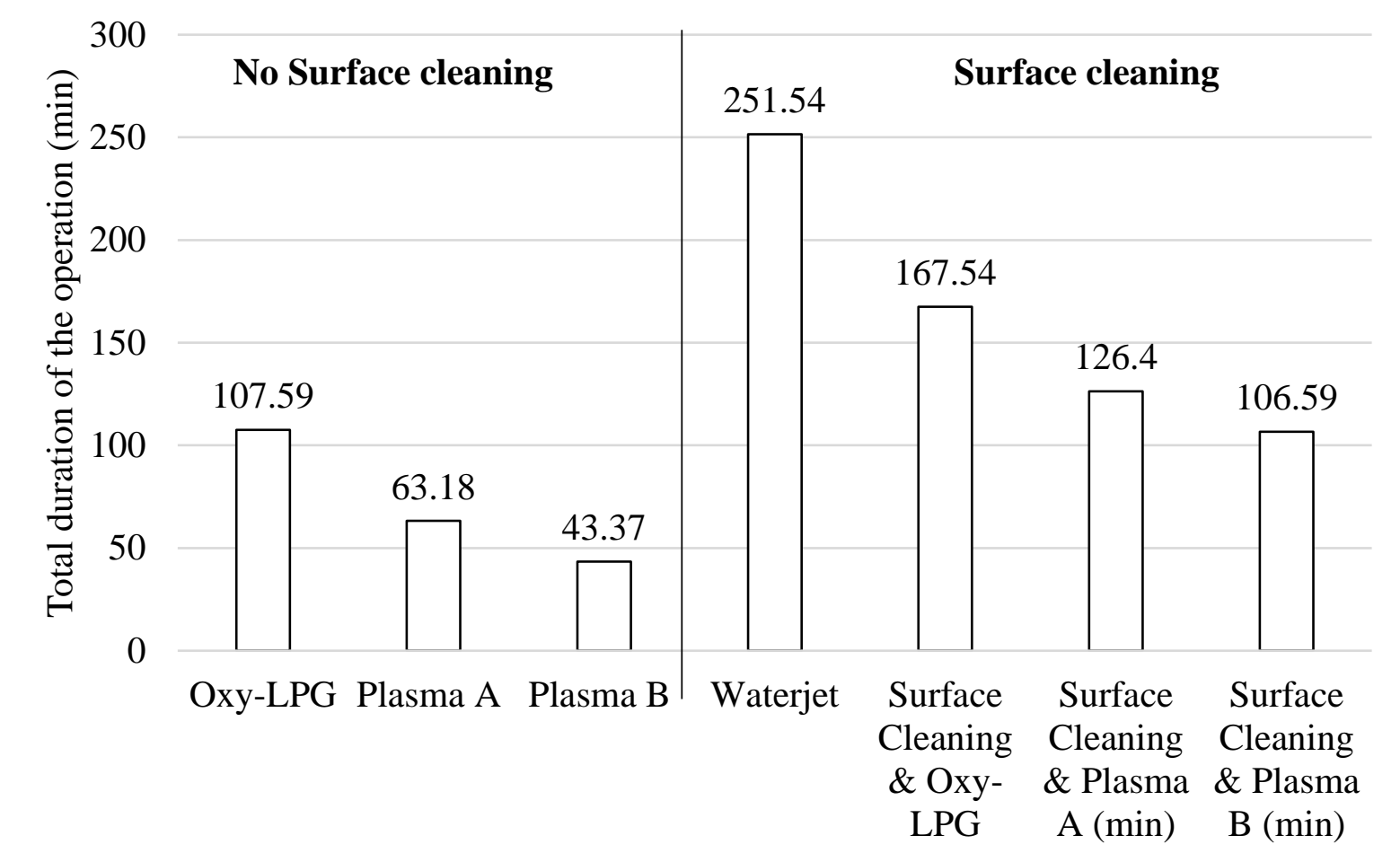

Figure 8: Comparison of the operation durations for different technologies during the dismantling process

Simulation results demonstrate that dismantling of the block using plasma (both options) is much faster compared to oxy-LPG (Figure 8). Even for a small operation like this, the dismantling time is approximately $60 \%$ faster compared to Oxy-LPG and $80 \%$ faster compared to abrasive waterjet cutting. It can be said that replacing the oxyfuel with plasma cutters can increase productivity in the cutting operation.

Moreover, even though the running cost of the plasma is more than the twice of the oxy-LPG's running cost, this operation is almost $50 \%$ cheaper using ( $€ 20.17 \& € 26.09)$ plasma than oxyLPG (€33.07) due to the reduction in the operation time (Figure 9). "Plasma B" model was selected to be able to operate on all the thicknesses of metals that the yard might come across, while "Plasma A" model was selected considering the thickness of this block specifically. In theory, it was thought that "Plasma B" would be over-specification for this operation due to the over-consumption of resources (gas and electricity) for the given metal thickness. However, even though the running costs of the "Plasma B" is higher compared to "Plasma A" model, the overall operation cost is lower for "Plasma B" model combined with the worker costs. This advantage is due to the higher cutting speed achieved in this model for the given thickness which lowers the overall operation time hence the use of worker's time. 
When the surface cleaning is involved, both the total time and cost of the operation increases by more than $50 \%$ for oxy-LPG cutting. However, even without the surface treatment, waterjet is still not a viable option due to the high operation cost, slow cutting speed and the time required to set up for each case (Figure 9).

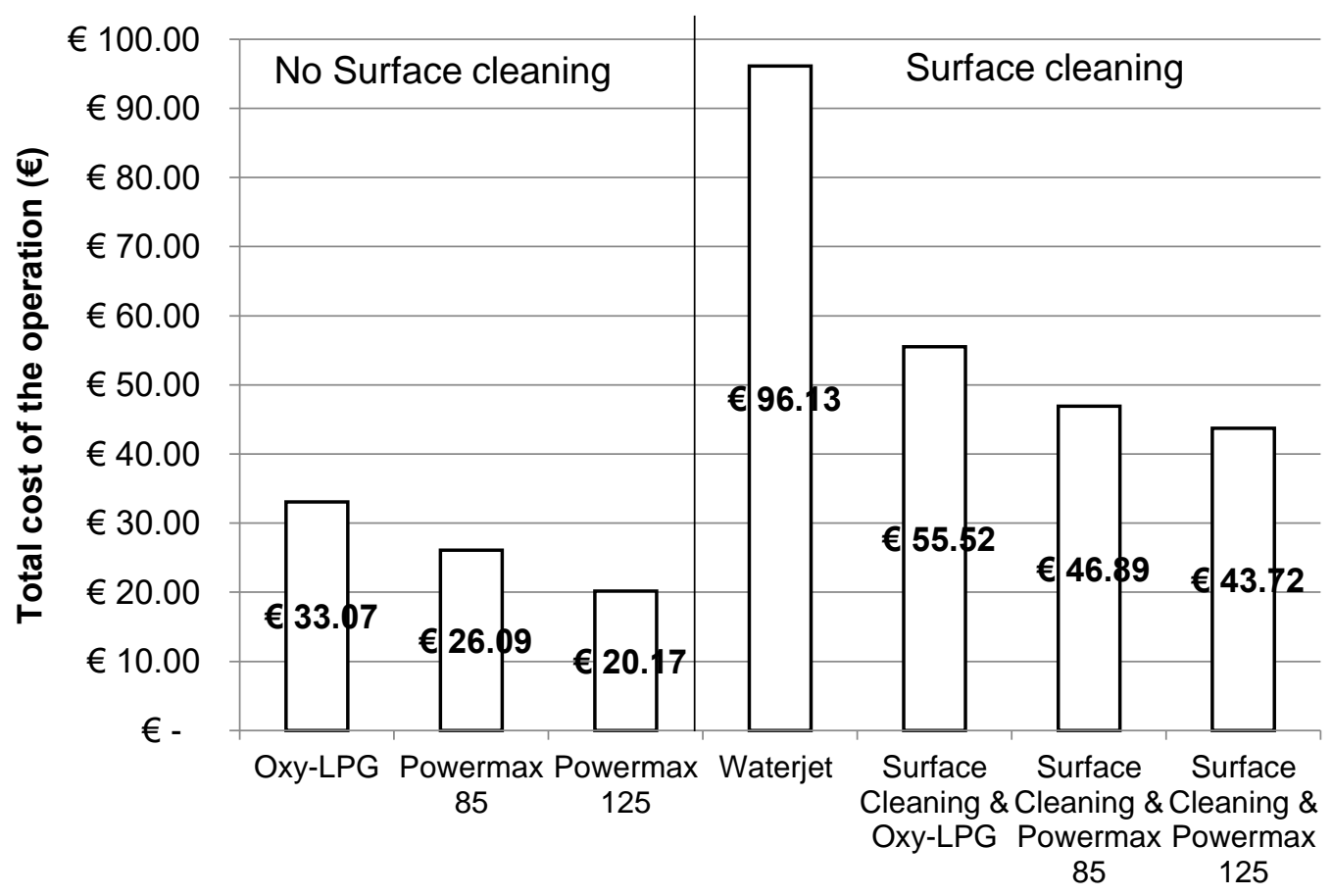

Figure 9: Comparison of the total cost of the operation ( $€$ )

When the simulation is run for a full workday, a worker can dismantle four blocks used in this specific case using oxyfuel cutting (Table 4). However, the same number can be achieved almost in half a workday (04:16:47) using Plasma A and almost three (02:51:29) hours with Plasma B. Moreover, after a full workday, seven (and the horizontal part of the last block) of this block can be entirely dismantled with Plasma A and 11 with Plasma B (Table 4).

Table 4: Total number of block dismantled if the operation was run through an eight-hour shift

\begin{tabular}{cc}
\hline Tool & $\begin{array}{c}\text { Number of Blocks after } \\
\text { a full day operation }\end{array}$ \\
\hline Oxy-LPG & 4 \\
Plasma A & 7 \\
Plasma B & 11 \\
\hline
\end{tabular}

The operational cost of running this equipment for the eight-hour shift was also given in Table 5. Oxy-LPG's operation cost is €147 and lowest for the all-day shift, but the four blocks that could generate the revenue around $€ 3 \mathrm{k}$ (scrap steel ton price was taken as $€ 270$ from Bimel Metal (2018)). The revenue given in Table 5 is theoretical and calculated directly through the total weight and the price per ton of scrap steel. In order to find the right revenue and profit, the costs associated with the operation, costs such as overhead, upkeep, maintenance, financial (banks and interests) and overall management costs of the ship recycling yard should also be considered.

Table 5: Total operation cost and revenue for an eight-hour shift 


\begin{tabular}{cccc}
\hline & Oxy-LPG & Plasma A & Plasma B \\
\hline Cost & $€ 147$ & $€ 188$ & $€ 220$ \\
Revenue & $€ 3021$ & $€ 5286$ & $€ 8306$ \\
\hline
\end{tabular}

Plasma B, with the highest cost of $€ 220$ for daily operation, generates the revenue around $€ 8.3 \mathrm{k}$ per working day (Table 5); therefore, based on the eight-hour shift simulation, Plasma $B$ is a better option on the economic perspective for the selected accommodation area block.

\subsection{Double Bottom Block}

Like the accommodation block; the simulation of the double bottom block dismantling was also run for ten replications. The comparison of the options is given in Table 6.

Table 6: Duration of the operation for different process options

\begin{tabular}{ccccc}
\hline & Waterjet (min) & $\begin{array}{c}\text { Surface } \\
\text { Cleaning \& Oxy- } \\
\text { LPG Cutting } \\
(\mathbf{m i n})\end{array}$ & $\begin{array}{c}\text { Surface } \\
\text { Cleaning \& } \\
\text { Plasma A (min) }\end{array}$ & $\begin{array}{c}\text { Surface } \\
\text { Cleaning \& } \\
\text { Plasma B (min) }\end{array}$ \\
\hline $\begin{array}{c}\text { Surface } \\
\text { cleaning } \\
\text { duration }\end{array}$ & - & $373: 18$ & $366: 45$ & $376: 16$ \\
\hline $\begin{array}{c}\text { Cutting } \\
\text { duration }\end{array}$ & $283: 16+220: 43$ & $112: 21+96: 55$ & $60: 10+55: 28$ & $46: 30+39: 21$ \\
\hline Total duration & $503: 59$ & $582: 34$ & $492: 23$ & $452: 36$ \\
\hline Cost & $€ 221.20$ & $€ 220.45$ & $€ 206.66$ & $€ 195.54$ \\
\hline
\end{tabular}

The economic performances of the oxy-fuel and waterjet are similar (Table 6) in the double bottom scenario ( $€ 221.20 \& € 220.45$ ), but waterjet is a faster alternative (503:59 min \& 582:34 $\mathrm{min}$ ) when the production performance is considered (Table 6). Similar to the accommodation block case, plasma cutting scenarios are again the best options for this operation. In ship recycling yards, surface treatment case is not a very common practice due to the cost and the time loss. Both case studies also show that the surface creates additional cost and increases the time considerably.

\section{Discussion}

Results of this study show that plasma cutting is a viable alternative to commonly used oxyfuel cutting for the daily metal cutting tasks in the yard. Plasma cutting can provide around $60 \%$ improvement in the productivity of the primary and secondary dismantling zones of the ship recycling yards for the selected case study. Even though the initial capital and consumable costs of the plasma cutting is more expensive compared to the oxy-fuel cutting, plasma cutting is superior to the oxy-fuel (LPG in this specific case). The initial cost of the plasma cutting is around $€ 10,000$ that is high compared to the $€ 300$ investment cost of the oxyfuel cutter. Moreover, on the operation expense, oxyfuel cutting (€21/hour total operation cost) is also much cheaper compared to plasma cutting (€33/hour). However, using plasma cutting, the difference in investment and operation be compensated due to the high performance, which compensates through the lower operation time, lower worker cost and higher throughput of the yard. One of the causes for performance difference is the fact that 
the oxyfuel requires the metal to be preheated before cutting, while plasma does not have this requirement. This also improves the quality of the steel as there is minimal slag on the cut edges. Even though it is generally not crucial for ship recycling, sometimes plates are sold as it is for direct reuse if they are in good condition. Plasma torches can cut non-ferrous metals and stainless steels while oxy-fuel torches cannot. This is important for the ship recycling business as some ships contains stainless steel parts (equipment, pipes, cargo holds, and so forth), as well as aluminium or cast-iron parts. Plasma torches can operate on these metals without any loss of productivity.

On the other hand, oxy-fuel torches allow better portability and mobility compared to the plasma. Even though the modern plasma systems are lighter and longer torch and connection options are available, they still require an electrical connection and compressed air source. Oxy-fuel cutters only require the torch and hose from the gas source to be operated. Plasma cutters can also achieve a similar portability, but it requires further investment by the yard for electricity connection point and additional compressed air sources.

The initial investment cost of a handheld plasma machine is more expensive compared to oxyLPG torch system. An appropriate plasma cutting machinery for ship recycling with the torch equipment cost varies around $€ 5,000$ to $€ 10,000$ depending on the maximum cutting capacity and torch length (cable), and consumables and replacements tips cost about $€ 10$ to $€ 40$ depending on the size (Lincolnelectric.com, 2017a, Weldersupply.com, 2017, Lincolnelectric.com, 2017b) On the other hand, oxy-fuel cutting equipment costs around $€ 300$ and $€ 1500$ and the cutting tips costs between $€ 10$ and $€ 20$. Also, there is always the cost of the oxygen and fuel costs and maintenance of the cylinders for safety. Additionally, there must be additional storage space for the storage of these tanks away from any source of fire, ignition or spark.

Waterjet cutters, on the other hand, were not found to be a feasible option for the industry due to the slow production rate, high investment cost and the time required for the setup. Waterjet cutting has its advantages, especially in the areas where hot cutting is dangerous. Advantages of waterjet over plasma cutting and oxyfuel cutting include: Operation at much lower temperatures thus no surface preparation is required if the part is contaminated with flammables, can cut a vast range of materials, both metal and non-metallic. Therefore, if the improvements in technology are achieved, they can become a feasible option for the ship recycling industry.

All these three technologies have their benefits and shortcomings and deciding which technology to use depends on factors such as material type to cut, metal thickness, available power resources, cost, environmental factors and location of the job.

In addition to the alternative technologies, improvements can be done on the oxyfuel cutting as well. The cutting speed of the oxy-fuel cutting is mainly dependent on the oxygen jet, but the fuel gas determines the rate of the preheating. Therefore, the choice of fuel gas directly affects the rate of preheating and duration of piercing (TWI-Global, 2015). In general, choice of fuel gas is made based on the cost of operation, however, according to the TWI, in a typical application, only $1-2 \%$ of the cost is related to the gas (The rest of the cost is distributed as; $50 \%$ overheads, $30 \%$ handling labour, $18 \%$ cutting labour) (TWI-Global, 2015). Hence, the focus can be given on the selection of fuel type to speed up the cutting process and reduce the labour time. The type of gas can affect the preheating times and piercing speed. In the 
ship recycling industry acetylene, propane and natural gas are used commonly as fuels. Natural gas and propane have lower flame temperatures compared to the maximum flame temperature of acetylene as fuel gas. This causes more extended heating and piercing times, but overall, the speed of the process is almost similar to each gas.

In a case study conducted by the company BOC, LPG and Acetylene are compared during the mechanised cutting operation of $25-\mathrm{mm}$ mild steel. It was found that by switching to acetylene from LPG, a $42 \%$ decrease in cost reduction was achieved. A similar study should be conducted for ship recycling. This topic is selected as a future study case. Similar to the study given in this paper, a study can be conducted to test different fuel types for the ship recycling industry. A study on the selection of fuel gas has never been conducted for ship recycling operations, and it would create a significant impact on the industry.

In addition to the fuel gas selection, another criterion that can be considered is the selection of the nozzle. During the field studies, it was observed that only one kind of cutting tips are used in cutting operations. The common understanding in the scrapping industry (and the ship recycling yards) is that the bigger tip is better suited for the job. However, choosing the wrong tip (too large or too small) only results in inefficiencies and waste for the user (Harris Products Group, n.d.). It is not possible to cut 1 " plate faster with a tip rated for 6" steel, or if a tip is only rated for $3 / 4$ " and used to cut 1 " plate, the process would be slower which will end wasting more gas (Harris Products Group, n.d.). Changing the cutting tip according to the steel thickness can improve the efficiency of ship recycling yards. In the literature, there is no study conducted that targets this problem for the ship recycling industry.

Another critical point criterion for oxy-fuel cutting is the purity of oxygen (ESAB, 2006). The purity of the oxygen used during oxy-fuel cutting should be at least $99.5 \%$ and $1 \%$ decrease in purity will result in $25 \%$ reduced cutting speed and $25 \%$ increased gas consumption (TWIGlobal, 2011). The additional study can be conducted to inspect the situation on the oxygen supply of the ship recycling industry. The oxygen suppliers of the industry should be inspected for the purity level of the oxygen they supply, especially to the developing countries like Bangladesh, Pakistan, and India.

As a future study, full optimisation of different ship recycling zones can be conducted using the discrete event simulation methodology. There are additional technologies that are being used in ship recycling processes; e.g. saws, mechanical shears, handheld shears (GENSCO, N.D., Atlas Copco, N.D.). There is a need for a study to support the decision of when to use which equipment for the maximum efficiency during the dismantling of an end of life ship. Also, there is a need for a framework to optimise the production of the ship recycling yard that is easy to use-even by anyone that has no simulation knowledge. This can support the industry, especially the industry in EU where the costs of the ship recycling yards are higher due to the high worker costs and laws and regulations. By increasing the productivity and reducing the cost, European ship recycling yards can be taken to a level to compete with the ship recycling yards in South Asia. The capital expense (CAPEX) and the operation expense (OPEX) of the new technologies should be taken into account in more detail in future study. Also, full life cycle cost of these equipment should be considered in the future study to achieve more accurate result.

Since the plasma cutting is a relatively new technology, there is no in-depth analysis for usage especially in the scrap steel industry and the shortcomings of this tool is not known especially 
in terms of health and safety. Therefore, an additional case study should also be conducted to identify the hazards and risks introduced/removed through the utilisation of plasma cutters. Emissions are also an important area that needs to be investigated during this case study to minimise the exposure of the workers to hazardous agents during their daily tasks.

\section{Conclusion}

The costs of the ship recycling yards will increase as a result of the Hong Kong and European ship recycling conventions. In the literature, no study focuses on the productivity improvement of the ship recycling yard or comparison of different cutting methods. Therefore, this study focused on the improvement of the efficiency in the secondary zone of a selected ship recycling through the consideration of different cutting methods and discrete event simulation. This study is unique regarding the data collection, investigation of ship recycling, and application of the discrete event simulation to ship recycling operation in detail. Two different blocks were selected to test three different cutting options in order to find the most feasible option for the ship recycling industry for the cutting operations.

This study demonstrated that plasma cutting is a reliable alternative to commonly used oxyfuel cutting through the use of discrete event simulation approach and theoretically plasma cutting can provide up to $60 \%$ improvement in the production of the yards. The high initial cost and high operation cost of plasma (compared to oxy-LPG) are compensated through high production performance and lower operation time at the primary and secondary dismantling zones of the ship recycling yards. Even though the initial capital and consumable costs of the plasma cutting is more expensive compared to the oxy-fuel cutting, plasma cutting is superior to the oxy-fuel (LPG in this specific case). The simulation results demonstrate that for the selected case blocks, operation cost was managed to be reduced around $40 \%$. Such improvement cases are extremely important for the ship recycling industry to demonstrate that safe and environmentally friendly ship recycling can still be competitive and profitable through engineering solutions and industry-academia collaboration.

Upcoming regulations will enforce stricter HSE rules for ship recycling yards which will impact on the running costs, process times and in turn overall productivity. Results for the case study yard show that performing surface treatment on steel plates before cutting with oxyfuel will increase the cost by $67 \%$. Ship recycling yards need to recognise these challenges before they encounter and develop alternative procedures to remain competitive.

A significant improvement in the performance and output in terms of steel was demonstrated for a ship recycling yard. In this study, discrete event simulations were employed to improve the production efficiency of ship recycling yards. Work done in this study demonstrated that the developed simulation framework is applicable to ship recycling yards and can be used for decision making by investors or other stakeholders. Also, the simulation framework that is proposed in this study can be used from a what-if perspective to tests various design alternatives which can aid decision making in facility improvements.

This study addresses an important gap in the ship recycling research through the development of a simulation method for ship recycling industry. This study first identified the cutting technologies suitable for the ship recycling industry and then compared the performance of these technologies using the discrete event simulation approach. The approach presented in this study is novel as cutting technologies were compared on real ship recycling processes for the first time. This approach will also help the industry to improve their operations. Through 
expanding the simulation models, it is possible to implement this approach for all different docking techniques; different surface preparation technologies, cutting technologies, lifting technologies to compare the economic performance in terms of cost, throughput and other user defined criteria. Also, this approach can also support the decision making processes in ship recycling yards to make investments or help planning in long-term through different whatif analysis examples presented in this study.

\section{References}

ADAMIDES, E., KARACAPILIDIS, N., PYLARINOU, H., KOUMANAKOS, D. \& HAPSAS, A. An integrated information system for supporting lean and green ship dismantling. Proceedings, Euroma 2006 Conference, Moving Up the Value Chain, K. Mendibil and A. Shamsuddin, editors, 2006. 18-21.

AHLUWALIA, R. S. \& GOVINDARAJULU, S. 2005. A Software Tool for Disposal of Obsolete Vessels. Journal of Ship Production, 21, 1-7.

ALKANER, S., DAS, P. K. \& SMITH, D. L. 2006a. Layout development for ship dismantling facilities. Proceedings of the First International Conference on Dismantling of Obsolete Vessels. Glasgow, UK.

ALKANER, S., DAS, P. K., SMITH, D. L. \& DILOK, P. 2006b. Comparative Analysis of Ship Production and Ship Dismantling. Proceedings of the First International Conference on Dismantling of Obsolete Vessels. Glasgow, UK.

ASOLEKAR, S. R. 2006. Status of management of solid hazardous wastes generated during dismantling of obsolete ships in India. Proceedings of the First International Conference on Dismantling of Obsolete Vessels. Glasgow, UK.

ATLAS COPCO. N.D. Hydraulic shears [Online]. Available: https://www.atlascopco.com/enuk/mrba/products/excavator-attachments/Steel-cutter [Accessed 16 February 2018].

BANKS, J. 2005. Discrete-event System Simulation, Pearson Prentice Hall.

BASÁN, N. P., ACHKAR, V. G., MÉNDEZ, C. A. \& GARCIA-DEL-VALLE, A. A heuristic simulation-based framework to improve the scheduling of blocks assembly and the production process in shipbuilding. 2017 Winter Simulation Conference (WSC), 3-6 Dec. 2017 2017. 3218-3229.

BIMEL METAL. 2018. ASIL ÇELIK FABRIKASININ GÜNCEL HURDA DEMIR FIYATLARI [Online]. Available: https://bimelmetal.com/asil celik hurda fiyatlari.html [Accessed 14 February 2018].

CEBRAL-FERNÁNDEZ, M., ROUCO-COUZO, M., PAZOS, M. Q., CRESPO-PEREIRA, D., VALLE, A. G. D. \& ABEAL, R. M. Application of a multi-level simulation model for aggregate and detailed planning in shipbuilding. 2017 Winter Simulation Conference (WSC), 3-6 Dec. 2017 2017. 3864-3875.

CHANG, Y.-C., WANG, N. \& DURAK, O. S. 2010. Ship recycling and marine pollution. Marine Pollution Bulletin, 60, 1390-1396.

CREESE, R. C., NANDESHWAR, A. \& SIBAL, P. 2002. Ship deconstruction cost models. AACE International Transactions, ES91.

DEMARIA, F. 2010. Shipbreaking at Alang-Sosiya (India): An ecological distribution conflict. Ecological Economics, 70, 250-260.

DESHPANDE, P. C., KALBAR, P. P., TILWANKAR, A. K., KHAIRKAR, S. K. \& ASOLEKAR, S. R. Fuel Consumption and Time - Motion Study for Manual Plate Cutting Operation: Case study from Ship Recycling Yards in Alang, India. Proceedings of the Third International Conference on Dismantling of Obsolete Vessels, 13-14 September 2010 2010 University of Strathclyde, Glasgow, Scotland, UK (2010).

DIVEST 2008-2011. Dismantling of Vessels with Enhanced Safety and Technology.

DIVEST 2009a. Deliverable 2.1 - State of the Art - Technical processes. DIsmantling of Vessels with Enhanced Safety and Technology.

DIVEST 2009b. Report on Selected RA Method, Deliverable No: 3.3 , 3.4, 3.5 and 3.7.

DIVEST 2011. D4.6: Value Model Development. 
DIVEST 2012. DIVEST Project Deliverable, D5.3 Addendum 1: Overview of Field Work.

EC. 2016. The EU Ship Recycling Regulation [Online]. Available: http://ec.europa.eu/environment/waste/ships/ [Accessed 5 September 2017].

ERONAT, A. H., BENGIL, F. \& NEŞER, G. 2019. Shipping and ship recycling related oil pollution detection in Çandarlı Bay (Turkey) using satellite monitoring. Ocean Engineering, 187, 106157.

ESAB 2006. Factors affecting quality in oxy-fuel cutting. In: ESAB (ed.).

GARMER, K., SJÖSTRÖM, H., HIREMATH, A. M., TILWANKAR, A. K., KINIGALAKIS, G. \& ASOLEKAR, S. R. 2015. Development and validation of three-step risk assessment method for ship recycling sector. Safety Science, 76, 175-189.

GENSCO. N.D. PORTABLE SCRAP \& DEMOLITION CUTTING TOOLS [Online]. Available: http://www.genscoequip.com/portable-scrap-demolition-cutting-tools [Accessed 16 February 2018].

GOO, B., CHUNG, H. \& HAN, S. 2019. Layered discrete event system specification for a ship production scheduling model. Simulation Modelling Practice and Theory, 96, 101934.

GUNBEYAZ, S. A. 2019. Designing efficient and contemporary ship recycling yards through discrete event simulation. $\mathrm{PhD}$, University of Strathclyde.

GUNBEYAZ, S. A., KURT, R. E. \& BAUMLER, R. J. W. J. O. M. A. 2019. A study on evaluating the status of current occupational training in the ship recycling industry in Bangladesh.

GUNBEYAZ, S. A., KURT, R. E. \& TURAN, O. Designing efficient contemporary ship recycling yards through discrete event simulation. Transport Research Arena TRA 2018, April 16-19, 20182018 Vienna.

HARRIS PRODUCTS GROUP. n.d. Oxy-Fuel Cutting - Choosing The Right Tips [Online]. Available: http://www.harrisproductsgroup.com/en/Expert-Advice/tech-tips/oxy-fuelcutting---choosing-the-right-tips.aspx [Accessed 17 January 2018].

HIREMATH, A. M., PANDEY, S. K. \& ASOLEKAR, S. R. 2016. Development of ship-specific recycling plan to improve health safety and environment in ship recycling yards. Journal of Cleaner Production, 116, 279-298.

HIREMATH, A. M., TILWANKAR, A. K. \& ASOLEKAR, S. R. 2015. Significant steps in ship recycling vis-a-vis wastes generated in a cluster of yards in Alang: a case study. Journal of Cleaner Production, 87, 520-532.

HOSSAIN, M. M. M. \& ISLAM, M. M. 2006. Ship breaking activities and its impact on the coastal zone of Chittagong, Bangladesh: towards sustainable management.

HOSSAIN, M. S., CHOWDHURY, R., JABBAR, M. A., SAIFULLAH, A. S. M. \& ATAUR RAHMAN, M. 2008. Occupational Health Hazards of Ship Scrapping Workers at Chittagong Coastal Zone, Bangladesh.

HOSSAIN, M. S., FAKHRUDDIN, A. N. M., CHOWDHURY, M. A. Z. \& GAN, S. H. 2016. Impact of ship-Breaking activities on the coastal environment of Bangladesh and a management system for its sustainability. Environmental Science \& Policy, 60, 84-94.

IDC, I. D. C. S. A. S. 2017. Hurda Teknik Ozellikleri [Online]. Available: http://www.izdemir.com.tr/Hurda Teknik Ozellikleri.asp [Accessed 20 April 2017].

IMO. 2009. The Hong Kong International Convention for the Safe and Environmentally Sound Recycling of Ships [Online]. Available: http://www.imo.org/en/About/conventions/listofconventions/pages/the-hong-konginternational-convention-for-the-safe-and-environmentally-sound-recycling-ofships.aspx [Accessed 05 September 2017].

JAGUSCH, K., SENDER, J. \& FLÜGGE, W. 2019. Transparency in the Design-Accompanying Production on Shipyards. Procedia CIRP, 81, 791-796.

JAIN, K. P. \& PRUYN, J. 2017. An Overview of the Global Ship Recycling Industry. Reference Module in Materials Science and Materials Engineering. Elsevier.

JU, S., SUNG, S., SHEN, H., JEONG, Y.-K. \& SHIN, J. G. 2020. System development for establishing shipyard mid-term production plans using backward process-centric simulation. International Journal of Naval Architecture and Ocean Engineering, 12, 2037. 
KOENIG, P. C., NARITA, H. \& BABA, K. 2002. Lean production in the Japanese shipbuilding industry? Journal of Ship production, 18, 167-174.

KOUMANAKOS, D., PYLARINOU, H., HAPSAS, A., KARACAPILIDIS, N. \& ADAMIDES, E. D. 2006. A simulation based decision support system for the dismantling of obsolete vessels. Proceedings of the First International Conference on Dismantling of Obsolete Vessels. Glasgow, UK.

KRISTOFFERSEN, S. 2012. Nextship-Lean Shipbuilding. Molde University College.

KURT, R. E., MCKENNA, S. A., GUNBEYAZ, S. A. \& TURAN, O. 2017. Investigation of occupational noise exposure in a ship recycling yard. Ocean Engineering, 137, 440449.

LINCOLNELECTRIC.COM. 2017a. Plasma Torches \& Options / Lincoln Electric [Online]. Available:

http://www.lincolnelectric.com/enus/equipment/accessories/Pages/plasma-torches.aspx [Accessed 1 May 2017].

LINCOLNELECTRIC.COM. 2017b. Tomahawk Plasma Cutting Systems [Online]. Available: http://www.lincolnelectric.com/en-us/equipment/plasmacutters/Pages/tomahawk.aspx [Accessed 1 May 2017].

LJUBENKOV, B., DUKIC, G. \& KUZMANIC, M. 2008. Simulation Methods in Shipbuilding Process Design. Strojniški vestnik, 54, 131-139.

MAHINDRAKAR, A. B., TILWANKAR, A. K. \& ASOLEKAR, S. R. 2008. Decontamination of Polluted Sediments from Ship Dismantling Yards in India: Laboratory Studies. The Second International Conference on Dismantling of Obsolete Vessels. Glasgow.

MCKENNA, S. A. \& DAS, P. K. 2008. Ship Breaking: Europe's Contribution to Tackling a Worldwide Problem. The Second International Conference on Dismantling of Obsolete Vessels. Glasgow.

MCKENNA, S. A., KURT, R. E. \& TURAN, O. 2012. A methodology for a 'design for ship recycling'. The Environmentally Friendly Ship. London: Royal Institution of Naval Architects.

MIKELIS, N. 2013. Ship recycling markets. BIMCO Bulletins. BIMCO.

NEŞER, G., ÜNSALAN, D., TEKOĞUL, N. \& STUER-LAURIDSEN, F. 2008. The shipbreaking industry in Turkey: environmental, safety and health issues. Journal of Cleaner Production, 16, 350-358.

NGO, S. B. P. 2015. NGO Shipbreaking Platform "Problems and Solutions [Online]. Available: http://www.shipbreakingplatform.org/problems-and-solutions/ [Accessed 4 December 2015].

NGO SHIP BREAKING PLATFORM 2017. NGO Ship Breaking Platform Annual Report-2016.

OZTURKOGLU, Y., KAZANCOGLU, Y. \& OZKAN-OZEN, Y. D. 2019. A sustainable and preventative risk management model for ship recycling industry. Journal of Cleaner Production, 238, 117907.

PHOGAT, S. 2013. An introduction to applicability of lean in shipbuilding. International Journal of Latest Research in Science and Technology, 2, 85-89.

PRAJAPAT, N., WALLER, T., YOUNG, J. \& TIWARI, A. 2016. Layout Optimization of a Repair Facility Using Discrete Event Simulation. Procedia CIRP, 56, 574-579.

PYLARINOU, C., KARACAPILIDIS, N. \& ADAMIDES, E. D. 2009. A Web-Based Decision Support System for the Planning of Vessel Dismantling Processes. Journal of Ship Production, 25, 161-167.

PYLARINOU, C., KOUMANAKOS, D., HAPSAS, A., KARACAPILIDIS, N. \& ADAMIDES, E. 2006. INTEGRATING SIMULATION INTO A WEB-BASED DECISION SUPPORT TOOL FOR THE COST EFFECTIVE PLANNING OF VESSEL DISMANTLING PROCESSES. In: INDUSTRIAL MANAGEMENT AND INFORMATION SYSTEMS LAB, M., UNIVERSITY OF PATRAS (ed.).

PYLARINOU, C., KOUMANAKOS, D., HAPSAS, A., KARACAPILIDIS, N. \& ADAMIDES, E. 2008. Integrating simulation into a web-based decision support tool for the cost effective planning of vessel dismantling processes.

RABBI, H. R. \& RAHMAN, A. 2017. Ship Breaking and Recycling Industry of Bangladesh; Issues and Challenges. Procedia Engineering, 194, 254-259. 
RAHMAN, S. M. M., HANDLER, R. M. \& MAYER, A. L. 2016. Life cycle assessment of steel in the ship recycling industry in Bangladesh. Journal of Cleaner Production, 135, 963971.

REDDY, M. S., JOSHI, H. V., BASHA, S. \& KUMAR, V. G. S. 2004. An assessment for energy potential of solid waste from ship scraping yard at Alang - Sosiya, India. Journal of Solid Waste Technology and Management, 30, 90-99.

RZEŹNIKIEWICZ, A. 2014. Cost comparison between oxyfuel and plasma cutting low alloy steel. Journal of Achievements in Materials and Manufacturing Engineering, 63, 8185.

SALIM, M. 2009. Livelihood Conditions and Health Hazard Risks of Workers in the Ship Breaking Industry: A Case Study on Sitakunda Ship Breaking Industrial Area, Chittagong. MS Research Project, Department of Geography and Environmental Studies, University of Chittagong, Bangladesh.

SENDER, J., ILLGEN, B. \& FLÜGGE, W. 2019. Digital design of shipbuilding networks. Procedia CIRP, 79, 540-545.

SHARMA, S. \& GANDHI, P. J. 2017. Scope and Impact of Implementing Lean Principles \& Practices in Shipbuilding. Procedia Engineering, 194, 232-240.

SHIMIZU, K., NAKAJO, Y., YAER, X., KATO, K., KIJIMA, T., TERAOKA, I. \& TERAMACHI, $\mathrm{H}$. Advanced Ship Recycling System-A Pilot Model Project in Muroran. Advanced Materials Research, 2012. Trans Tech Publ, 1827-1830.

SHIN, J. G., SONG, Y. J., LEE, D. K. \& WOO, J. H. 2009. A concept and framework for a shipyard layout design based on simulation. Journal of Ship production, 25, 126-135.

SINGH, R., CHERRIE, J. W., RAO, B. \& ASOLEKAR, S. R. 2020. Assessment of the future mesothelioma disease burden from past exposure to asbestos in ship recycling yards in India. International Journal of Hygiene and Environmental Health, 225, 113478.

SINHA, S. 1998. Ship Scrapping and the environment-the buck should stop! Maritime Policy \& Management, 25, 397-403.

SONG, Y.-J., LEE, D.-K., CHOE, S.-W., WOO, J.-H. \& SHIN, J.-G. 2009. A simulation-based capacity analysis of a block-assembly process in ship production planning. Journal of the Society of Naval Architects of Korea, 46, 78-86.

TSRA 2009. Welcome to Turkish Ship Recycling Association, Informative PowerPoint presentation.

TWI-GLOBAL. 2011. Oxyfuel cutting - process and fuel gases [Online]. Available: http://www.twi-global.com/technical-knowledge/job-knowledge/oxyfuel-cuttingprocess-and-fuel-gases-049/ [Accessed 11 December 2017].

TWI-GLOBAL. 2015. Cutting processes - application of oxyfuel cutting - Job Knowledge 50 [Online]. Available: $\quad$ https://www.twi-global.com/technical-knowledge/jobknowledge/cutting-processes-application-of-oxyfuel-cutting-050/ [Accessed].

URANO, Y. 2012. The current picture and the future vision of the ship recycling industry: the contributions of Japan to achieving sustainable, safe and environmentally sound recycling of ships.

VELUMANI, S. \& TANG, H. 2017. Operations Status and Bottleneck Analysis and Improvement of a Batch Process Manufacturing Line Using Discrete Event Simulation. Procedia Manufacturing, 10, 100-111.

WEI, Y., DING, Z., HUANG, H., YAN, C., HUANG, J. \& LENG, J. 2019. A non-contact measurement method of ship block using image-based 3D reconstruction technology. Ocean Engineering, 178, 463-475.

WELDERSUPPLY.COM. 2017. Thermal Dynamics CUTMASTER 52 Plasma Cutter \#1-51301 | Thermal Dynamics / Cutmaster 52 / Plasma Cutter / Welding Machine / Welder [Online]. Available: https://www.weldersupply.com/P/459/ThermalDynamicsCUTMASTER [Accessed 1 May 2017].

WOO, J. H. \& OH, D. 2018. Development of simulation framework for shipbuilding. International Journal of Computer Integrated Manufacturing, 31, 210-227. 
YANMAZ, M. 2005. The effects of climate change and EU accession process on the iron and steel sector. In: Presentation by the Erdemir group on sustainable steel industry. (in Turkish). Ankara;.

ZHANG, Z., DAI, Y. \& LI, Z. 2012. Deviation diagnosis and analysis of hull flat block assembly based on a state space model. Journal of Marine Science and Application, 11, 311320. 